\title{
MENIMBANG SALAD BOWL DALAM SKEMA ONE STATE SOLUTION SEBAGAI SOLUSI MENYELESAIKAN PERMASALAHAN ISRAEL- PALESTINA
}

\author{
Endri Ahmadi \\ Universitas Pertahanan \\ thedomlank@gmail.com \\ Kukuh Setyo Pambudi \\ Universitas Pertahanan \\ kukuhpambudi@ymail.com
}

\begin{abstract}
Abstrak
Permasalahan antara Palestina dan Israel merupakan salah satu permasalahan yang sudah sangat lama terjadi dan belum menampakkan akan segera selesai. Akar permasalahan yang kompleks dan menahun membuat permasalahan ini sulit untuk diakhiri. Tulisan ini bertujuan untuk membahasas salah satu model resolusi yang dapat ditawarkan kepada kedua negara, yakni one state solution. Solusi melebur kedua negara menjadi satu adalah solusi yang banyak dipandang realistis sekaligus skeptis karena berbagai alasan. Optimisme atas solusi ini datang ketika melihat kondisi saat ini yang sangat tidak menguntungkan pada Palestina baik secara teritorial maupuan secara bangunan ketatanegaraan. Selanjutnya, telah banyak masyarakat Palestina yang menjadi warga negara Israel. Disisi lain, pandangan skeptis akan muncul karena menganggap Palestina menjadi pihak yang paling dirugikan. Oleh karena itu, salad bowl diajukan dalam tulisan ini sebagai solusi untuk tidak menghilangkan jejak identitas Palistina, namun akan memberi Palestina kejelasan status. Oleh karena itu dibutuhkan proses yang panjang dan personil UNTSO yang memiliki culture Inteligence yang baik. Sehingga dapat menjadi penengah dan negoisator ulung dalam menghasilkan kesepakatan yang diinginkan. Peran social inteligence penting karena hal ini akan melibatkan peleburan negara dengan tetap menjaga identitas sosial. Tulisan ini akan mengunakan kajian literatur sebagai metode utama dalam mengali data dan fakta. Hasil dari analisis diharapkan dapat menjadi masukan bagi UNTSO dalam menyelesaikan permasalahan antara Palestina dan Israel.
\end{abstract}

Keywords: salad bowl, one state solution, identitas sosial, culture inteligence, UNTSO 


\section{PENDAHULUAN}

Konflik yang terjadi antara Palestina dan Israel merupakan salah satu masalah yang berakar sangat panjang dan memiliki dimensi sejarah yang rumit. Dalam melihat permasalahan ini diperlukan sudut pandang yang sangat objektif dan imparsial untuk menelurkan sebuah rumusan yang mampu dan efektif menyelesaikan benang kusut permasalahan. Hal ini penting dilakukan karena banyak pihak mensalahartikan dan memiliki pemahaman yang salah atas konflik ini dengan hanya menaikkan isu agama tanpa memperhatikan dimensi yang lainnya. Alhasil, pemahaman banyak orang terdistorsi dan mudah bersimpati pada hal yang tidak terlalu sesuai dengan pokok permasalahan.

Krisis yang terjadi di Palestina-Israel meruapakan salah satu permasalahan yang berakar panjang dan berawal sejak tahun 1920 an. Wilayah ini sebenarnya merupakan bekas wilayah yang dikuasai oleh Kesultanan Ottoman atau saat ini dikenal dengan negara Turki sebelum jatuh ke tangan Kerajaan Inggris (Smith, 2004). Selama empat ratus tahun wilayah ini masuk dalam kekuasaan Ottoman dan ada dibawah otoritas gubernur jendral Damaskus (Lewis, 1980). Wilayah ini pada awalnya dinamakan Palestina, ketika Inggris menguasai pertama kali di tahun 19171918. Pergeseran kekuasaan yang dikendalikan oleh kerajaan Inggris membawa dampak cukup besar bagi wilayah ini, karena terdapat dinamika yang kemudian memerdekakan wilayah ini dan menjadikannya dua negara yakni Israel dan Palestina.

Titik awal permasalahan bermula ketika Inggris mengeluarkan sebuah statemen yang kemudian dikenal sebagai deklarasi Balfour. Dalam deklasrasi ini Inggris menyatakan akan membuat Palestina sebagai wilayah yang ditujukan sebagai rumah bagi orang-orang Yahudi. Deklarasi ini belakangan menjadi salah satu dasar pendirian negara Israel sampai dengan hari ini (Renton, 2007). Pendirian negara ini sebenarnya mendapatkan perlawanan dan penolakan keras, selain itu meningalkan konflik yang sampai sekarang mungkin masih terang di ingatan. Selain deklarasi Balfour, yang sebenarnya tidak terlalu gamblang membicarakan bahwa tanah Palestina akan menjadi rumah orang Yahudi, terdapat mandat Palestina yang berusaha membagi wilayah ini menjadi beberapa sebaran. Berikut merupakan gambaran wilayah yang awalnya diusulkan oleh PBB dalam "Palestine Mandate". 


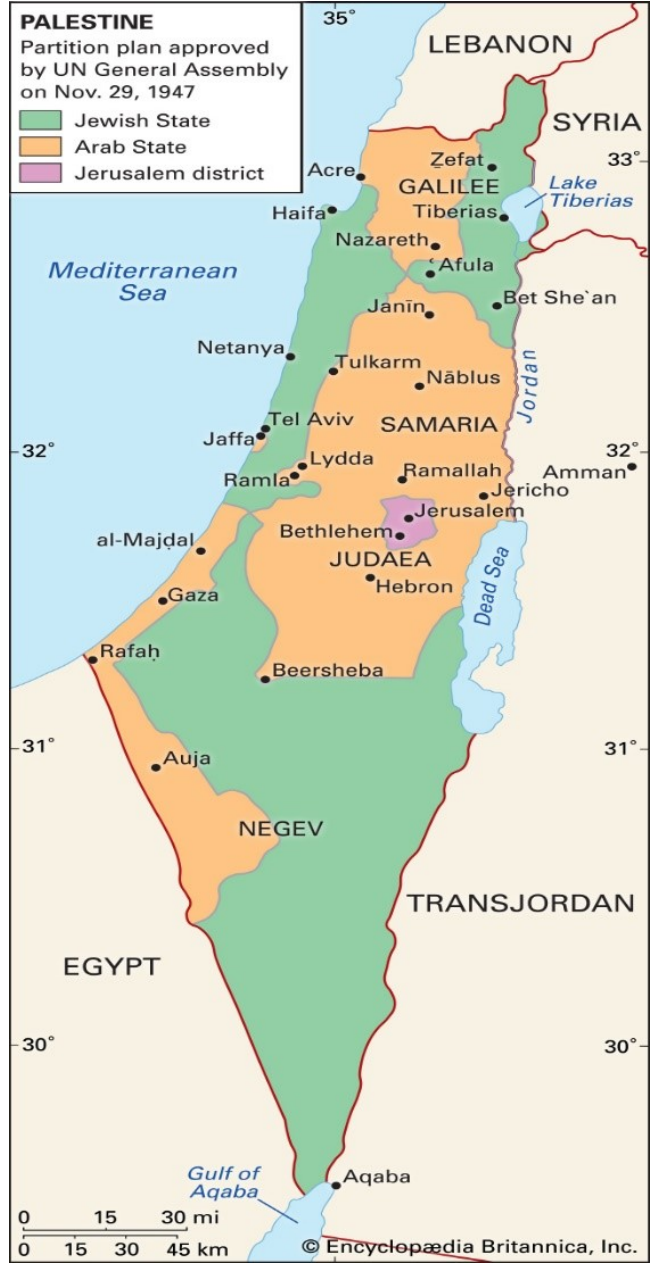

(Encyclopædia Britannica, 2019)

Palestine Mandate merupakan salah satu resolusi pertama yang diajukan oleh PBB dalam menyelesaikan permasalahan antara Israel dan Palestina. Setelah adanya pemisahan wilayah, PBB membuat sebuah badan yang menjadi pengawas dan supervisor dalam menangani konflik di wilayah ini. Badan bentukan PBB ini dinamakan United Nation Truce Supervision Organization atau disingkat UNTSO. Tugas dari badan ini adalah untuk memberikan supervisi demi terwujudnya perdamaian di wilayah TimurTengah, khususnya wilayah Israel yang bersitegang dengan beberapa negara di sekitarnya, termasuk Palestina itu sendiri. meskipun telah lama berdiri, sejak 29 Mei 1948, sampai saat ini UNTSO tidak pernah menghasilkan sebuah jalan keluar yang mengembirakan, bahkan Nachmias (1996) menuliskan bahwa UNTSO merupakan salah satu misi perdamaian PBB yang gagal dan telah usang untuk diteruskan.

Beberapa resolusi atas permasalahan Palestina-Israel telah lama dicanangkan, bahkan beberapa diantaranya telah disahkan dalam bentuk resolusi oleh PBB. Meskipun demikian, usaha untuk mewujudkan perdamaian di tanah Palestina dan Israel tidak boleh mengendur begitu saja. UNTSO sebenarnya masih memiliki potensi dalam mengakhiri konflik menahun ini, meskipun harus banyak mengejar ketertingalan. Salah satu yang mungkin harus menjadi perhatian adalah pemahaman lintas budaya bagi para personil ketika menjalankan tugasnya (Indrawan, 2017).

UNTSO juga perlu mempersiapkan langkah dan solusi yang mutakhir demi terciptanya perdamaian. Hal ini mengingat kondisi saat ini sangat jauh berbeda dengan kondisi di waktu awal UNTSO didirikan. Minimal pencapaian yang harus dapat direalisasikan adalah pengakhiran kekerasan yang nyaris ramai menghiasi tiap tahun pemberitaan Internasional di wilayah ini. Kekerasan dan agresi yang banyak dilakukan antara kedua pihak juga sebenarnya telah banyak melangar hukum - hukum Internasional (Yuliantiningsih, 2009).

Setelah kekerasan dapat dikendalikan, langkah berikutnya yang dapat ditempuh adalah dengan mengusahakan adanya kesepakatan atas wilayah dan ketatanegaraan. Selama ini Israel dan Palestina saling 
mengklaim menjadi pemilik sah atas wilayah kedua negara (Burge, 2012). Oleh karena itu, dalam mendukung kestabilan wilayah, perlu kiranya merumuskan sebuah tata wilayah dan tata pemerintahan yang dapat diterima oleh kedua negara. Dalam hal ini, penulis ingin mengangkat solusi satu negara sebagai jalan yang paling mungkin dicapai.

One state solution merupakan satu usulan yang dicanangkan pertama kali oleh Muamar Qadafi. Usulan ini mengharuskan kedua belah pihak yang selama ini saling berkonflik untuk melebur menjadi satu negara yang tidak lagi memandang agama dan ras (Qaddafi, 2009). Usulan ini banyak mengundang pro-kontra, karena menganggap dengan adanya satu negara dan posisi Israel yang lebih kuat, hanya akan membuat aneksasi Israel terhadap Palestina. Namun, dalam kondisi yang seperti sekarang ini lebih banyak pihak yang memandang bahwa one state solution adalah solusi yang paling masuk akal (Munayyer, 2019).

Meskipun banyak pihak yang skeptis yang mungkin berkembang, penulis meyakini jalan satu negara merupakan solusi terbaik. Oleh karena itu, harus ada beberapa penyesuaian dan persyaratan yang diajukan dalam usulan ini. Salah satunya adalah dengan menjamin tegaknya identitas Palestina, meskipun nantinya tidak ada lagi negara Palestina. Identitas ini akan terangkum dan sejajar dengan identitas Israel. Konsep Salad Bowl diusulkan oleh penulis dalam hal ini.

\section{PEMBAHASAN}

Beberapa permasalahan yang mungkin menjadi pertimbangan dalam solusi satu negara ini diantaranya adalah formulasi yang sulit dicapai dan identitas yang terlanjur mengkristal. Meskipun demikian, terdapat beberapa kondisi yang sebenarnya masih memberikan harapan bahwa rencana ini bisa dijalankan. Beberapa diantaranya adalah banyaknya masyarakat yang berasal dari Arab-Palestina yang menetap di wilayah Israel. Kemudian, potensi dukungan dari banyak negara sangat mungkin di dapatkan atas solusi satu negara.

Fakta bahwa kondisi saat ini telah banyak berubah tidak seperti tahun 1948 dimana UNTSO pertama didirikan adalah hal yang tidak boleh dilupakan. Mayoritas masyarakat Palestina saat ini merasa dirinya tengah ada dalam penjajahan dan memiliki keinginan yang kuat untuk merdeka, atau minimal melakukan pembalasan dendam pada Israel (Sa'di, 2002). Memori dan luka lama yang menumpuk, bahkan masih harus ditambahkan oleh memori baru atas tindakan kekerasan yang masih banyak terjadi saat ini, telah banyak merubah pola pikir masyarakat. Bahkan diantara mereka, telah tumbuh bibit militansi untuk membela tanah air mereka dengan jalan teror (Yuliantiningsih, 2009). Oleh karena itu, kekerasan seakan telah mencapai titik nadir, dan harus secepatnya dihentikan.

Sesungguhnya terdapat banyak usulan yang pernah dimasukkan dalam rangka menyelesaikan konflik yang terjadi. Secara garis besar pernah dikenal dalam beberapa kerangka diantaranya solusi dua negara, tiga negara, dan satu negara. Solusi dua atau bahkan tiga negara adalah solusi yang lama mengambang. Dalam kedua solusi tersebut, terdapat misi untuk tetap memisahkan Palestina dari Israel. Tujuannya tak lain karena menganggap Palestina tidak dapat 
disatukan dengan Israel dan memori kelam yang pernah terjadi (Ophir, 2007). Solusi ini sebenarnya juga masuk akal, terutama jika melihat kondisi bahwa Palestina juga telah memiliki pemerintahan tersendiri. Namun, kondisi ini akan sulit tercapai karena Palestina tidak hanya memiliki satu pemerintahan, namun terdapat perpecahan antara para politisi dan pejuang di negeri ini.

Hamas dan Fatah adalah dua faksi yang saling mengklaim pemerintahan yang sah di Palestina. Kebuntuan antara kedua faksi ini juga sering menimbulka konflik tersendiri di wilayah Palestina. Bahkan effort untuk memberikan damai di Palestina lebih banyak digulirkan untuk membuat kedua faksi ini untuk dapat berdamai (Schanzer, 2008). Kedua faksi memiliki pandangan yang berbeda atas perjuangan memerdekakan Palestina. Fatah lebih memilih untuk melakukan jalur-jalur diplomasi dan meja perundingan sebagai sarana utama. Sedangkan Hamas banyak melakukan aksiaksi bersenjata dan kekerasan untuk mewujudkan tujuannya (Sayigh, 2010).

Salah satu alasan yang menjadi alasan utama solusi satu negara sebagai solusi paling realistis adalah perpecahan yang terjadi di Palestina. Ketika ada solusi yang kemudian makin memecah belah wilayah ini menjadi beberapa negara kecil, maka kestabilan kawasan akan makin sulit tercapai. Hal ini harus disadari karena konflik antara tiap faksi di Palestina bukanlah konflik yang sepele dan tidak memiliki akar yang panjang. Rivalitas antara kedua faksi ini bahkan telah meluas melibatkan narasi keagamaan dalam memenangkan kontestasi. Tak jarang, konflik yang terjadi bukanlah melawan Israel sebagai rival bangsa, namun melawan kekuatan antar faksi yang makin membuat Palestina terkoyak (Milton-Edwards, 2007).

Oleh karena itu, penulis berpandangan bahwa mempersatukan Palestina-Israel adalah jalan yang logis dan sangat realistis. Namun, perlu dicatat bahwa persiapan dan proses penyatuan keduanya juga harus teliti dipersiapkan dan dijalankan. Selain model integrasi yang harus unik dan menghormati otonomi Palestina sebagai bangsa, persiapan UNTSO dalam menjalankan rencana ini juga harus dipertimbangkan. Integrasi dengan model salad bowl sangat disarankan oleh penulis. Selain itu, Cultural Inteligent juga harus mendapat tempat yang cukup sentral dalam pemilihan awak UNTSO untuk memastikan dapat berfungsi dengan baik.

\section{Salad Bowl}

Model integrasi dengan mengunakan Salad Bowl merupakan salah satu metode yang efektif dalam menyatukan unsur yang bergam kedalam satu wadah. Pemodelan ini pertama kali dilakukan di Amerika Serikat untuk mengantikan model melting pot yang ditingalkan karena dianggap menghapus jejak identitas dan budaya masyarakat (Bhattacharya, 2008). Model ini pun akhirnya cukup sukses, dan banyak ditiru oleh negara lain, salah satunya Indonesia.

Salad bowl membuat sebuah suasanya yang asimilatif bagi masyarakat yang terdiri dari beberapa suku, bangsa, ataupun negara untuk hidup bersama dalam satu wilayah dan mengangkat satu identitas umum yang disepakati bersama. Oleh karena itu akan sangat menjanjikan untuk diterapkan pada Israel dan Palestina apabila one state solution jadi diterapkan. Hal ini merujuk atas keberhasilan yang pernah dicapai oleh 
Amerika Serikat dalam memastikan imigran yang pernah membanjiri negaranya untuk dapat berguna dalam pembangunan negara.

Masyarakat Palestina diharapkan nantinya untuk dapat diakui sebagai warga negara yang sah dan berdaulat. Selain itu, kepastian untuk Palestina dan tentu Israel agar dapat mempertahankan identitas bangsanya menjadi penting. Negara yang satu itu nanti sangat diharapkan menjadi negara yang mampu menjamin keberagaman dan tidak membeda-bedakan perlakuan seperti yang pernah diusulkan oleh Qaddafi (2009) sehingga tidak membuat masyarakatnya terasing. Namun, dalam kenyataan hari ini, penulis berpandangan bahwa struktur negara Israel dapat menjalankan hal ini. Palestina dapat dilebur ke dalam Israel dengan beberapa catatan.

Kepastian akan otonomi daerah yang menjadi tempat tingal masyarakat Palestina menjadi yang pertama. Masyarakat Palestina perlu untuk mendapatkan kebebasan atas otoritas lokalnya, meskipun mereka tetap ada dalam naungan satu negara. Selanjutnya adalah memastikan tidak ada sentimen agama yang diangkap dalam urusan tata negara di Israel, karena setelah Palestina bergabung, frase negara Yahudi harusnya dibuang jauhjauh.

Status kewarganegaraan yang sama juga penting untuk diperjuangkan. Israel dan Palestina harus mendapatkan status kewarganegaraan yang setara dan diakui baik di tingkat negara maupun di tingkat internasional. Sehingga kedepannya krisis kemanusiaan dapat dihindari, dan memastikan kekerasan untuk dapat dirat dengan hukum positif yang pasti. Salah satu efek yang dapat dicapai dalam proses ini adalah, perekonomian yang akan terangkat. Masyarakat Palestina akan lebih bak secara finansial dibandingkan sebelumnya. Demikian juga secara psikis, mereka tidak akan lagi merasa terjajah dan memiliki negaranya.

\section{Cultural Inteligent}

Dalam mewujudkan konsep salad bowl dalam kerangka solusi satu negara, harus dibarengi dengan supervisor yang kompeten dan mampu membaca budaya masyarkat lokal. Hal ini penting dalam memastikan negoisasi ddapat berjalan dengan lancar. Oleh karena itu UNTSO harusnya dibangun ulang dengan mengendepankan awak yang selain cakap dalam urusan perundingan, juga memiliki kecerdasan budaya yang baik.

Cultural inteligence (CI) merupakan sebuah konsep yang mengukur kemampuan seseorang untuk mengenali dan secara efektif berinteraksi dengan orang dari berbagai kebudayaan. Konsep ini sangat efektif dalam memastikan seseorang untuk sukses dalam menalankan tugasnya di seting lintas budaya. Seperti penelitian yang pernah dilakukan oleh Ang, et al., (2007) yang menemukan bahwa dalam setting lintas budaya orang yang memiliki kemampuan CI akan cenderung memiliki performa kerja, adaptasi, dan pengambilan keputusan yang lebih baik. Sehingga sangat mendukung kegiatan yang dilakukan dalam setting lintas budaya.

Berdasarkan beberapa hal di atas, cultural inteligence dapat menjanjikan keberhasilan yang lebih besar bagi UNTSO dalam menjalankan tugas dan fungsinya. Hal ini dapat menangulangi apa yang telah gagal dicapai pada penugasan sebelumnya. Oleh karena itu sangat disarankan dalam 
pembentukan tim UNTSO nantinya dapat memastikan Cultural Inteligence yang cukup.

\section{KESIMPULAN}

Konsep one state solution merupakan konsep yang menurut penulis paling ideal untuk direalisasikan di masa sekarang. Solusi satu negara ini juga harus dilekngkapi dengan kebijakan asimilasi yang berupa salad bowl sehingga identitas masyarakat tidak tercerabut dan proses penggabungan dapat berjalan dengan lebih baik.

Selain itu, UNTSO sebagai badan PBB yang bertugas untuk memberikan supervisi pada Israel dan Palestina dapat didayagunakan kembali untuk melanjutkan tugasnya sesuai dengan rumusan one state solution. Pertimbangan lain yang harus dilakukan adalah dengan mengedepankan cultual inteligence dalam perekrutan anggotanya. Diharapkan dengan personil yang memiliki cultural inteligene yang baik, proses penyelesaian masalah akan berangsur lebih baik dan negoisasi yang dilakukan nantinya akan lebih lancar.

\section{SARAN}

Berkaitan dengan konflik Palestina dan Israel yang menjadi fokus dalam tulisan ini, terdapat beberapa saran yang diajukan. Pertama, mempertimbangkan one state solution sebagai jalan yang bisa dan sangat mungkin diambil. One state tidak berarti melemahkan Palestina sebagai bangsa karena tetap haris diberikan beberapa affirmative action dan otonomi wilayah.
Kedua, pembentukan one state solution harus dilakukan oleh panitia yang profesional dan kompeten. Oleh karena itu memberdayakan UNTSO kembali untuk menuntaskan tugas lamanya adalah jalan yang dapat diambil. Pembentukan tim baru UNTSO haruslah mengedepankan Cultural Inteligence sebagai dasar perekrutan. Konsep ini akan memastikan personil UNTSO dapat menjalankan tugas dan diplomasi lebih lancar.

Terakhir, konsep asimilasi melalui salad bowl perlu diagendakan apabila solusi dapat tercapai. Hal ini dilakukan guna merekatkan kedua bangsa menjadi satu dalam wadah negara yang baru dan tata pemerintahan yang dilakukan ulang. Melalui salad bowl kedua bangsa yakni Israel dan Palestina tidak akan kehilangan jati dirinya. Meskipun demikian, keduanya akan mampu bekerja sama dan hidup dalam satu negara dengan baik dan harmonis.

Pemikiran ini cukup radikal dan mungkin mengundang banyak pihak untuk tidak setuju. Oleh karena itu, penulis membuka diri untuk berdiskusi lebih jauh, serta menunggu masukan dan kajian lain yang mungkin dapat menyempurnakan pemikiran ini.

\section{Daftar Refensi}

Ang, S., Van Dyne, L., Koh, C., Ng, K. Y., Templer, K. J., Tay, C., \& Chandrasekar, N. A. (2007). Cultural intelligence: Its measurement and effects on cultural judgment and decision making, cultural adaptation and task performance. Management and organization review, 335-371. 
Bhattacharya, U. \&. (2008). Melting pot or salad bowl: Some evidence from US investments abroad. Journal of Financial Markets, 228-258.

Burge, G. M. (2012). Palestina Milik Siapa? Jakarta: BPK Gunung Mulia.

Encyclopædia Britannica. (2019, January 17). UN partition plan: Israel and Palestine. Retrieved from Encyclopædia Britannica: https://www.britannica.com/event/Ar ab-Israeli-wars\#/media/1/31439/3081

Indrawan, R. M. (2017). PEMAHAMAN KOMPETENSI LINTAS BUDAYA BAGI UNTSO (UNITED NATION TRUCE SUPERVISION ORGANIZATION) UNTUK MEMECAH KEBUNTUAN DALAM PENYELESAIAN KONFLIK PALESTINA-ISRAEL. Verity - UPH Journal of International Relations.

Lewis, B. (1980). Palestine: On the History and. The International History Review, 1-12.

Milton-Edwards, B. (2007). Hamas: victory with ballots and bullets. Global Change, Peace \& Security, 301-316.

Munayyer, Y. (2019, December 15). There Will Be a One-State Solution, But What Kind of State Will It Be? Retrieved from Foreign Affair: https://www.foreignaffairs.com/articl es/israel/2019-10-15/there-will-beone-state-solution
Nachmias, N. (1996). UNTSO: Obsolte peacekeeping? Peacekeeping \& International Relations, 25.

Ophir, A. (2007). The two-state solution: providence and catastrophe. Journal of homeland security and emergency management.

Qaddafi, M. (2009, January 22). The OneState Solution. Retrieved from The New York Times: www.nytimes.com/2009/01/22/opinio $\mathrm{n} / 22$ qaddafi.html? $\mathrm{ref}=$ opinion

Renton, J. (2007). The Zionist Masquerade. The Birth of the Anglo-Zionist Alliance. London: Palgrave MacMillan.

Sa'di, A. H. (2002). Catastrophe, memory and identity: Al-Nakbah as a component of Palestinian identity. Israel Studies, 7(2), , 175-198.

Sayigh, Y. (2010). Hamas rule in Gaza: three years on. Middle East Brief, 1-9.

Schanzer, J. (2008). Hamas vs. Fatah: the struggle for Palestine. USA : St. Martin's Press.

Smith, C. D. (2004). Palestine and the ArabIsraeli conflict. St. Martin's: Bedford.

Yuliantiningsih. (2009). Agresi Israel Terhadap Palestina Perspektif Hukum Humaniter Internasional. . Jurnal Dinamika Hukum, 135-144. 